\title{
Analisis Implementasi Manajemen Pengendalian Risiko Dalam Upaya Tercapainya Tujuan Organisasi (Studi Kasus Pada Kantor Wilayah Direktorat Jenderal Perbendaharaan Provinsi Nusa Tenggara Barat)
}

Abdurrahman', L. Hendra Maniza ${ }^{2}$, Maya Lestari ${ }^{3}$

1Prodi Administrasi Publik, Universitas Muhammadiyah Mataram, email 2Prodi Administrasi Bisnis, Universitas Muhammadiyah Mataram,

3Prodi Administrasi Publik, Universitas Muhammadiyah Mataram,

\section{INFO ARTIKEL}

\section{Riwayat Artikel:}

Diterima: 28-3-2018

Disetujui: 29-3-2018

\section{Kata Kunci:}

1. Implementasi

2. Manajemen

3. Pengendalian resiko

4. Tujuan Organisasi

\begin{abstract}
ABSTRAK
Abstrak: Risiko adalah ancaman atau kemungkinan suatu tindakan atau kejadian yang menimbulkan dampak yang berlawanan dengan tujuan yang ingin dicapai. Dalam hal ini manajemen pengendalian risiko peranan yang sangat penting untuk menyelesaikan berbagai risiko yang akan timbul pada organisasi. Kantor Wilayah Direktorat Jenderal Perbendaharaan Provinsi Nusa Tenggara Barat menerapkan manajemen pengendalian risiko agar risiko yang mungkinan akan terjadi dimasa yang akan datang dapat dikelola dengan baik dan tujuan/sasaran organisasi dapat tercapai. Tujuan penelitian ini untuk mendeskripsikan implementasi manajemen pengendalian risiko.
\end{abstract}

Penelitian ini adalah penelitian kualitatif dengan pendekatan deskriptif. Dalam penelitian ini peneliti mendeskripsikan implementasi dan proses manajemen pengendalian risiko menggunakan indikator analisis Edward III yaitu komunikasi dan sumberdaya dan langkah-langkah yang diambil untuk mengendalikan risiko dalam upaya tercapainya tujuan organisasi. Oleh karena itu peneliti melakukan observasi, wawancara, dan dokumentasi kemudian menganalisisnya dengan pengumpulan data, reduksi data,display data, dan penarikan kesimpulan.

Dari hasil analisis tersebut diperoleh bahwa imlementasi manajemen pengendalian risiko sudah mencakup 2 indikator yaitu komunikasi dalam bentuk rapat bulanan, triwulanan dan rapat semesteran, sumberdaya dengan jumlah dan mutu serta fasilitas yang memadai. Kemudian implementasi manajemen pengendalian risiko sudah berjalan dengan aktif melalui pengendalian/penanganan risiko dengan memilih opsi pengendalian yang sesuai untuk mengurangi kemungkinan terjadinya risiko dan menurunkan dampak risiko sehingga tujuan/sasaran kantor Wilayah Direktorat Jenderal Perbendaharaan Provinsi Nusa Tenggara Barat tercapai dengan risiko yang tidak begitu besar.

\section{Abstrack}

Risk is a threat or command Action or event that emphasizes something to be achieved. In this case it is a very useful management for the various kinds that will arise in the organization. The Regional Office of the Directorate General of Treasury of West Nusa Tenggara Province implements the management of controls in order to enable what will happen in the future which will be arranged properly and appropriately. The purpose of this study is to describe the implementation of risk control management. 
Keyword:
1. Implementation
2. Management
3. Risk control
4. Organization Objectives

This research is a qualitative research with descriptive approach. In this research, the researcher describes the implementation and implementation of management by using Edward III analysis that is communication and strategy and steps needed to reach the organization goal. Researchers therefore use, interview, and documentation and then analyze it by digging data, reducing data, displaying data, and reducing conclusions.

From these results obtained that there are two indicators of communication in the form of monthly, quarterly and semester, resources with the number and quality and adequate facilities. Then implement the management quickly and effectively with appropriate to reduce the speed and speed of the main goal of the Directorate treasury General of West Nusa Tenggara Province with a scope that is not so large.

\section{Latar Belakang}

Aktivitas organisasi sektor publik senantiasa berubah dan berkembang seiring dengan perubahan di lingkungan internal dan eksternal organisasi. Perubahan di lingkungan internal berupa perbaikan metode operasi (misalnya perubahan dari manual ke otomatisasi) biasanya dapat dikendalikan oleh manajemen dan perubahan di lingkungan eksternal, seperti perubahan iklim demokrasi dan peraturan, berada di luar kontrol organisasi.

Tuntutan perubahan dan peningkatan kapabilitas organisasi memunculkan risiko (risk) dan sekaligus peluang (opportunities) bagi organisasi. Risiko berkenaan dengan kemungkinan terjadinya kegagalan dan kerugian bagi organisasi. Risikoberskala rendah tidak menghawatirkan bagi organisasi, namun risiko berskala besardapat berdampak pada tidak tercapainya tujuan dan misi dari organisasi. Kegagalantujuan dan misi bagi organisasi publik dapat mengakibatkan distrus(ketidakpercayaan) dari publik atas pelayanan yang diberikan, dalam kondisi terjelek dan sebagaimana yang pernah terjadi, distrust dapat menyebabkan hilangnya oranisasi yang bersangkutan.

Definisi dari risiko adalah ancaman atau kemungkinan suatu tindakan atau kejadian yang menimbulkan dampak yang berlawanan dengan tujuan yang ingin dicapai (Ferry N. Idroes 2008: 4). Kemungkinan kejadiannya mengancam pencapaian tujuan dan sasaran instansi pemerintah. Pada umumnya, risiko tidak dapat dihilangkan ataupun dihindari begitu saja, tetapi risiko dapat dikelola dengan baik menurut kebutuhan instansi. Biasanya risiko yang terjadi tidak dapat dihilangkan secara langsung, namun risiko tersebut dapat dikurangi melalui tindakantindakan untuk meminimalisir dampaknya. Kegagalan tercapainyatujuan dan misi organisasi publik dapat mengakibatkan distrust(ketidakpercayaan) dari publik atas pelayanan yang diberikan.

Sumber risiko berasal dari dalam (internal) maupun dari luar (eksternal). Berdasarkan tingkat risiko dibedakan menjadi: (1) risiko manajemen yang mengarah kepada yang bersifat strategis/kebijakan dan finansial, yang didalamnya pemerintahan bisa disejajarkan dengan level kebijakan/program dengan indikator kinerja yang berupa impact/outcome dan (2) risiko operasional yang mengarah kepada kegiatan teknis maupun operasional, yang di dalam pemerintahan bisa disejajarkan dengan level kegiatan dengan indikator output.

Tindakan manajemen risiko diambil oleh para praktisi untuk merespon bermacam-macam risiko. Manajemen risiko dapat membantu suatu instansi dalam menetapkan strategi ke depannya, kemudian meninjau kembali startegi yang telah diterapkan sehinga dapat relevan dengan situasi yang terus berkembang. Manajemen risiko dirancang untuk dapat mengidentifikasi, 
menganalisa dan mengendalikan risiko yang mungkin terjadi pada setiap proses aktivitas yang dijalankan. Apabila instansi pemerintah telah memiliki dan menjalankan manajemen risiko yang efektif maka risiko yang dihadapi oleh pemerintah telah diidentifikasi dan dikelola sedemikian rupa sampai dengan tingkatan tertentu yang dapat diterima oleh pemerintah (Nurharyanto, 2009).

Instansi yang berhasil menerapkan manajemen risiko yang efektif memiliki keunggulan kompetitif jangka panjang yang dapat menjaga stakeholders mendapatkan hak mereka masing-masing, karena sistem manajemen risiko yang didesain dengan baik akan memastikan bahwa seluruh aktivitas yang mengandung risiko dievaluasi dengan hati-hati oleh manajer dan pekerja yang bertanggungjawab.

Tujuan nasional yang tertera pada UUD 1945 menjadi acuan bagi setiap instansi pemerintahan. Melalui visi misi serta tugas dan fungsi Kantor Wilayah Direktorat Jenderal Perbendaharaan Provinsi Nusa Tenggara Barat maka tujuan nasional akan tercapai. Berdasarkan Peraturan Menteri Keuangan Republik Indonesia Nomor 262/PMK.01/2016 tentang Organisasi dan Tata Kerja Instansi Vertikal Direktorat Jenderal Perbendaharaan, dengan salah satu fungsi pengelolaan hutang dalam negeri pada pusat manajemen Obligasi Negara (PMON) serta tugas pokok yang dijalankan oleh Kantor Wilayah Direktorat Jenderal Perbendaharaan Provinsi Nusa Tenggara Barat adalah melaksanakan koordinasi, supervisi asistensi, bimbingan teknis, dukungan teknis, monitoring, evaluasi, analisis, kajian, penyusunan laporan dan pertanggungjawaban dibidang perbendaharaan berdasarkan peraturan perundang-undangan.

Untuk meningkatkan pembangunan nasional khususnya di Nusa Tenggara Barat pemerintah pusat menyalurkan anggaran melalui Kantor Wilayah Direktorat Jenderal Perbendaharaan Provinsi Nusa Tenggara Barat yang bertujuan untuk meningkatkan pembangunan daerah sesuai dengan visi dan misi Kantor Wilayah Direktorat Jenderal Perbendaharaan Provinsi Nusa Tenggara Barat. Tidak mudah untuk mencapai tujuan serta tugas dan fungsi dengan hasil yang optimal sesuai visi dan misi tersebut, akan banyak muncul masalahmasalah yang akan berdampak pada organisasi dan memiliki risiko.
Risiko

pada lembaga/instansi pemerintahan yang muncul pada kementerian keuangan berdasarkan penyebab risiko, yang sering terjadi adalah risiko fiskal, risiko kebijakan, risiko kepatuhan, risiko legal, risiko fraud, risiko reputasi, risiko operasional dan akan berdampak pada beban keuangan negara, penurunan reputasi, sanksi pidana, perdata dan/atau administratif, kecelakaan kerja, gangguan terhadap layanan organisasi serta penurunan kinerja. Selain berdampak pada lembaga juga berdampak pada masyarakat jika dalam proses pelayanan terhambat.

Dengan demikian manajemen pengendalian risiko mempunyai peranan yang sangat penting untuk meyelesaikan berbagai risiko yang akan timbul dengan tujuan meminimalisir risiko dalam berbagai langkah dan proses demi tercapainya tujuan/sasaran pada Kantor Wilayah Direktorat Jenderal Perbendaharaan Provinsi Nusa Tenggara Barat.

Melihat pentingnya penerapan manajemen pengendalian risiko, Kantor Wilayah Direktorat Jenderal Perbendaharaan Provinsi Nusa Tenggara Barat menerapkan manajemen pengendalian risiko berdasarkan peraturan menteri keuangan republik indonesia No.171/PMK.01/2016 tentang penerapan manajemen risiko dilingkungan kementerian keuangan dalam Rangka mengamankan sasaran strategis organisasi.

\section{Tinjauan Pustaka}

\section{a. Pengertian Implementasi Kebijakan}

Menurut Van Metter dan Van Horn dalam Agustino (2008:195) menjelaskan bahwa implementasi kebijakan adalah tindakan-tindakan yang dilakukan baik oleh individu-individu/pejabat-pejabat atau kelompok-kelompok pemerintah atau swasta yang diarahkan pada tercapainya tujuantujuan yang telah digariskan dalam keputusan kebijakan.

Menurut Mazmanian dan Sabatier dalam Agustino (2008:196) menjelaskan bahwa implementasi kebijakan adalah pelaksanaan keputusan kebijakan dasar, biasanya dalam bentuk undang-undang, namun dapat pula berbentuk perintahperintah atau keputusan-keputusan eksekutif yang penting atau keputusan badan peradilan. Lazimnya, keputusan tersebut mengidentifikasikan masalah-masalah yang ingin diatasi, menyebutkan secara tegas 
tujuan dan sasaran yang ingin dicapai, dan berbagai cara untuk menstrukturkan atau mengatur proses implementasinya.

Berdasarkan rumusan implementasi kebijakan sebagaimana dikemukakan diatas, maka implementasi kebijakan dapat dimaknai sebagai pelaksanaan kegiatan/aktifitas mengacu pada pedomanpedoman yang telah disiapkan sehingga dari kegiatan/aktifitas yang telah dilaksanakan tersebut dapat memberikan dampak/akibat bagi stakeholder pada sebuah instansi dan dapat memberikan kontribusi dalam menanggulangi masalah yang menjadi sasaran program.

Adapun teori implementasi dari Edward III dalam Subarsono (2011 : 90-92) mengenai implementasi, bahwa implementasi kebijakan dipengaruhi oleh empat variabel, yaitu :

1) Komunikasi, yaitu keberhasilan implementasi kebijakan mensyaratkan agar implementor mengetahui apa yang harus dilakukan, dimana yang menjadi tujuan dan sasaran kebijakan harus ditransmisikan kepada kelompok sasaran (target group), sehingga akan mengurangi distorsi implementasi.

2) Sumberdaya, meskipun isi kebijakan telah dikomunikasikan secara jelas dan konsisten, tetapi apabila implementor kekurangan sumberdaya untuk melaksanakan, maka implementasi tidak akan berjalan efektif. Sumber daya tersebut dapat berwujud sumber daya manusia, misalnya kompetensi implementor dan sumber daya finansial.

3) Disposisi, adalah watak dan karakteristik yang dimiliki oleh implementor, seperti komitmen, kejujuran, sifat demokratis. Apabila implementor memiliki disposisi yang baik, maka implementor tersebut dapat menjalankan kebijakan dengan baik seperti apa yang diinginkan oleh pembuat kebijakan. Ketika implementor memiliki sikap atau perspektif yang berbeda dengan pembuat kebijakan, maka proses implementasi kebijakan juga menjadi tidak efektif.

4) Struktur Birokrasi, Struktur organisasi yang bertugas mengimplementasikan kebijakan memiliki pengaruh yang signifikan terhadap implementasi kebijakan. Aspek dari struktur organisasi adalah Standard Operating Procedure (SOP) dan fragmentasi. Struktur organisasi yang terlalu panjang akan cenderung melemahkan pengawasan dan menimbulkan red-tape, yakni prosedur birokrasi yang rumit dan kompleks, yang menjadikan aktivitas organisasi tidak fleksibel.

\section{b. Unsur-Unsur Manajemen}

Untuk mencapai tujuan yang telah ditetapkan, seorang manajer membutuhkan sarana manajemen yang disebut dengan unsur manajemen. Menurut pendapat yang dikemukakan oleh Manullang sebagaimana dikutip oleh Mastini tentang unsur manajemen tersebut, terdiri atas manusia, material, mesin, metode, dan markets, setiap unsur-unsur tersebut memiliki penjelasan dan peranan bagi suatu memanajemen agar untuk mengetahui bahwa manajemen memiliki unsur-unsur perlu dimanfaatkan unsur-unsur manajemen tersebut (Agustini, 2013:61). Untuk mengetahui hal tersebut dapat dijelaskan unsur-unsur manajemen seperti di bawah ini.
a. Manusia (Man)
b. Material (Material).
c. Mesin (Machine).
d. Metede (Method)
e. Uang (Money)
f. Pasar (Markets)

\section{c. Fungsi Manajemen}

Fungsi manajemen adalah sebagai berikut menurut Henry Fayol dalam buku Malayu (2007:17) ada :

a. Planning(Perencanaan)

Menunjukan tujuan-tujuan yang hendak dicapai selama suatu masa yang akan datang dan apa yang harus di perbuat agar dapat mencapai tujuantujuan itu.

b. Organizing(Pengorganisasian)

Mengelompokan dan menentukan berbagai kegiatan penting dan memberikan kekuasaan untuk melaksanakan kegiatan-kegiatan itu.

c. Commanding (Pengarahan)

Memberikan arahan agar dapat menunaikan tugas mereka masingmasing.

\section{d. Coordinating (Motivasi)}


Mengarahkan atau menyarulkan perilaku manusia ke arah tujuan-tujuan.

e. Controlling(Pengawasan)

Mengukur Pelaksanaan dengan tujuan-tujuan, menentukan sebab-sebab penyimpangan-penyimpangan dan mengambil tindakan-tindakan korektif dimana perlu.

\section{d. Pengertian Risiko}

Risiko didefnisikan sebagai sesuatu yang dapat menciptakan rintangan dalam pencapaian tujuan organisasi, karena faktor internal dan eksternal, tergantung dari tipe risiko yang ada dalam situasi tertentu (Kanchu dan Kumar, 2013).Menurut Karim (2004: 63) secara bahasa risiko berarti suatu kejadian negatif, uncertainty (ketidakpastian) dan the future is unknown(waktu yang akan datang tidak dapat diketahui).Risiko adalah probabilitas suatu hasil yang berbeda dari hasil yang diharapkan (Karim, 2004: 64).Sedangkan Menurut Idroes (2008: 4), risiko adalah ancaman atau kemungkinan suatu tindakan atau kejadian yang menimbulkan dampak yang berlawanan dengan tujuan yang ingin dicapai.

Kesimpulannya risiko adalah bahaya, akibat atau konsekuensi yang dapat terjadi akibat sebuah proses yang sedang berlangsung atau kejadian yang akan datang.

\section{Metodologi Penelitian}

Penelitian ini adalah penelitian kualitatif dengan pendekatan deskriptif. Penelitian kualitatif adalah penelitian yang bermaksud untuk memahami fenomena tentang apa yang dialami oleh subjek penelitian secara holistik, dan dengan cara deskripsi dalam bentuk katakata dan bahasa pada suatu konteks khusus yang alamiah dan dengan memanfaatkan berbagai metode alamiah (Moleong, 2006:6). Sedangkan penelitian deskriptif menurut Arikunto (2005: 234) adalah penelitian yang dimaksudkan untuk mengumpulkan informasi mengenai status gejala yang ada, yaitu keadaan gejala menurut apa adanya pada saat penelitian dilakukan. Lebih lanjut Arikunto menjelaskan bahwa penelitian deskriptif tidak dimaksudkan untuk menguji hipotesis tertentu, tetapi hanya menggambarkan apa adanya tentang suatu variabel, gejala atau keadaaan.
Lokasi penelitian ini dilaksanakan Pada Kantor Wilayah Direktorat Jenderal Perbendaharaan Provinsi Nusa Tenggara Barat Jl. Majapahit No. 10 Mataram (83127).

Secara garis besar data dalam penelitian ini berupa data primer dan data sekunder.

a. Data Primer, di ambil dengan melakukan observasi dan wawancara dengan pegawai kantor Wilayah Direktorat Jenderal Perbendaharaan Provinsi Nusa Tenggara Barat yaitu pada bagian struktur pengelola risiko dan bagian kepatuhan internal.

b. Data Sekunder, didapatkan pada dokumen-dokumen buku pedoman pengelola risiko Kantor Wilayah Direktorat Jenderal Perbendaharaan Provinsi NTB.

\section{Hasil dan Pembahasan}

a. Implementasi Manajemen Pengendalian Risiko Dalam Upaya Tercapainya Tujuan Organisasi Pada Kantor Wilayah Direktorat Jenderal Perbendaharaan Provinsi Nusa Tenggara Barat

Pelaksanaan tata kelola instansi Kantor Wilayah Direktorat jenderal Perbendaharaan provinsi Nusa Tenggara Barat berjalan sesuai dengan arah tujuan yang telah ditentukan menjadi dasar landasan lingkup Kantor Wilayah Direktorat Jenderal Perbendaharaan Provinsi Nusa Tenggara Barat dapat berjalan dengan efektif dan efisien. Maka Kantor Wilayah Direktorat Jenderal Perbendaharaan Provinsi Nusa Tenggara Barat yang dimaksud adalah kantor vertikal yang dipimpin oleh seorang kepala Kantor Wilayah ini membentuk Manajemen Risiko. Dalam hal ini risiko adalah tolok ukur untuk menentukan keberhasilan Kantor Wilayah Direktorat Jenderal Perbendaharaan Provinsi Nusa Tenggara Barat.

Menurut Edward III bahwa implementasi kebijakan dipengaruhi oleh empat indikator yaitu komunikasi, sumberdaya, disposisi, struktur birokrasi. Akan tetapi pada analisis penelitian ini saya menggunakan komunikasi dan sumber daya yang akan menjadi pisau analisis untuk menjawab implementasi dari manajemen pengendalian risiko.

1. Komunikasi 
Komunikasi yaitu keberhasilan implementasi kebijakan mensyaratkan agar implementor mengetahui apa yang harus dilakukan, dimana yang menjadi tujuan dan sasaran kebijakan harus ditransmisikan kepada kelompok sararan. Suatu program akan dapat dilaksanakan dengan baik apabila jelas bagi pelaksana. Hal ini menyangkut proses penyampaian informasi yang disampaikan.

Berdasarkan pengamatan yang peneliti lakukan, bahwa komunikasi yang dilakukan antara pejabat kewenangan pengelola risiko selalu mengadakan rapat pada setiap bulan, triwulanan, rapat persemester atau setiap 6 bulan sekali dan brieffing yang dilaksanakan setiap senin pagi oleh seluruh pegawai. Hal tersebut bertujuan agar Peraturan Menterri Keuangan mengenai implementasi manajemen pengendalian risiko ini dapat di kontrol dan menyambung komunikasi dengan waktu yang sudah ditetapkan.

Berdasarkan data yang diperoleh dapat diketahui bahwa komunikasi yang dilakukan dengan tujuan penyampaian informasi menyangkut keputusan menteri keuangan mengenai manajemen risiko ini dilaksanakan setiap bulan, triwulanan dan setiap semester. Rapat bulanan merupakan rapat yang dilakukan tingkat kantor wilayah, rapat triwulanan murupakan rapat yang melibatkan seluruh kepala Kantor Pelayanan Perbendaharaan Negara, dan rapat persemester dilaksanakan oleh pejabat pelaksana manajemen pengendalian risiko.

Pada rapat tesebut, tidak semua pegawai yang ada pada Kantor Wilayah Direktorat Jenderal Perbendaharaan Provinsi Nusa Tenggara Barat dilibatkan dalam setiap rapat manajemen pengendalian risiko. Seluruh pegawai akan diwakili oleh setiap kepala bidang dan satu kepala seksi. Hasil rapat tersebut akan disampaikan oleh setiap kepala bidang pada pegawai yang ada pada bidang masing-masing.

Jadi komunikasi yang dilakukan antara pejabat pengelola risiko dengan pegawai Kantor Wilayah Direktorat Jenderal Perbendaharaan Provinsi Nusa Tenggara Barat sudah dilakukan berdasarkan Standar Operasional Prosedur (SOP) yang sudah ditetapkan melalui rapat yang diselenggarakan tiap bulan, triwulanan dan 6 bulan sekali.

2. Sumberdaya
Meskipun isi kebijakan telah dikomunikasikan secara jelas dan konsisten, tetapi apabila implementor kekurangan sumberdaya untuk melaksanakan, maka implementasi tidak akan berjalan efektif. Sumber daya tersebut dapat berwujud sumber daya manusia meliputi 4 komponen, yaitu staf yang cukup (jumlah dan mutu), informasi yang dibutuhkan guna pengambilan keputusan, kewenangan yang cukup guna melaksanakan tugas dan tanggung jawab serta fasilitas yang dibutuhkan dalam pelaksanaan.

Berdasarkan pengamatan yang peneliti lakukan pada saat penelitian, sumber daya yang ada pada Kantor Wilayah Direktorat Jenderal Perbendaharaan Provinsi Nusa Tenggara Barat sudah tergolong cukup baik. Dalam hal ini sumber daya manusia sudah memadai (jumlah dan kemampuan) dapat melaksanakan implementasi dari manajemen pengendalian risiko secara sempurna karena mereka dapat melakukan pengawasan terhadap risiko mulai dari diri sendiri yang sudah dibekali dengan budaya sadar risiko. Berikut jumlah pegawai berdasarkan jumlah dan jenjang pendidikan akan disajikan dalam bentuk tanbel dibawah ini :

Tabel 4.1 Jumlah dan Jenjang Pendidikan Pegawai

\begin{tabular}{|c|c|c|}
\hline No & $\begin{array}{c}\text { Jenjang } \\
\text { Pendidikan }\end{array}$ & Jumlah \\
\hline 1 & S2 & 7 \\
\hline 2 & S1 & 27 \\
\hline 3 & D3 & 1 \\
\hline 4 & D1 & 4 \\
\hline 5 & SMA & 15 \\
\hline 6 & SMP & 1 \\
\hline \multicolumn{3}{|c|}{ Total } \\
\hline
\end{tabular}

(Sumber : Arsip Kanwil Ditjen Perbendaharaan $N T B)$

Berdasarkan tabel 4.1 diatas dapat diketahui bahwa pendidikan pegawai sebagian besar jenjang pendidikan (S1) mempunyai 27 orang pegawai, pendidikan paling tinggi merupakan jenjang pendidikan (S2) yang mempunyai 7 orang pegawai dan jenjang pendidikan terendah yaitu SMP dengan jumlah pegawai 1 orang.

Pejabat yang termasuk dalam Struktur Pengelola Risiko yaitu : Taukhid, S.E., 
M.Sc.IB., M.B.A selaku kepala kanwil dan kepala unit pengelola risiko. I Gusti Bagus Eddy Pramana Madurdja, S.E. M.M selaku kepala bidang SKKI dan pelaksana harian dan sub manajer pada unit pengelola risiko.Koencara Boedi Samboso, Drs selaku kepala seksi kepatuhan internal dalam bisang SKKI sekaligus Sekretaris dalam unit pemilik risiko. Moh. Meizar Zulkarnain, S.E, Khairudinsyah, dan sugeng Priyadi (D3) selaku pelaksana pada bidang SKKI sekaligus Anggota dalam unit pengelola risiko.

Berdasarkan data yang peneliti peroleh tersebut, pada struktur organisasi pengelola risiko, jenjang pendidikan pemilik risiko selaku kepala kanwil yaitu (S2), Pelaksana harian dan Koordinator Sub Menejer selaku kepala bidang Supervisi KPPN dan Kepatuhan Internal jenjang pendidikannya (S2), Sekretasi pengelola risiko jenjang pendidikannya (S1), dan 3 anggota pengelola risiko jenjang pendidikan S1, D3, SMA.

Dalam hal sumberdaya, struktur pengelola risiko mempunyai jenjang pendidikan yang cukup baik untuk mengelola manajemen pengendalian risiko lingkup kantor wilayah direktorat jenderal perbendaharaan provinsi NTB disertai dengan fasilitas yang memadai serta dana yang mencukupi.

Berdasarkan Data yang diperoleh dapat disimpulkan bahwa pelaksanaan dari penerapan manajemen pengendalian risiko berdasarkan PMK No. 171/PMK.01/2016 sudah berjalan sesuai 2 indikator tersebut. Mulai dari Komunikasi yang dilakukan antara pejabat pengelola risiko dengan seluruh pegawai Kantor Wilayah Direktorat jenderal Perbendaharaan Provinsi Nusa Tenggara Barat, sumberdaya dengan jumlah yang cukup dan fasilitas sarana prasarana yang memadai dapat mendukung proses tercapainya tujuan organisasi.

Pada Kantor Wilayah Direktorat Jenderal Perbendaharaan Provinsi Nusa Tenggara Barat, implementasi dari manajemen pengendalian risiko yaitu berdasarkan proses manajemen pengendalian risko. Proses tersebut antara lain :

a. Komunikasi dan konsultasi
Pada Kantor Wilayah Direktorat Jenderal Perbendaharaan Provinsi Nusa Tenggara Barat, komunikasi dan konsultasi dilakukan disetiap tahapan proses manajemen risiko, baik kepada para pemangku kepentingan internal maupun pemangku kepentingan eksternal.

Bentuk dari komunikasi dan konsultasi pada Kantor Wilayah Direktorat Jenderal Perbendaharaan Provinsi Nusa Tenggara Barat antara lain yaitu rapat berkala, rapat insidental, focused group discussion dan forum pengelola risiko.

Berdasarkan data yang diperoleh dapat diketahui bahwa rapat yang diadakan setiap bulan, triwulanan dan setiap semester adalah bentuk dari komunikasi dan konsultasi mengenai manajemen pengendalian risiko yang sudah dilaksanakan 3 tahun terakhir semenjak manajemen risiko diterapkan pada Kantor Wilayah Direktorat Jenderal Perbendaharan Provinsi Nusa Tenggara Barat.

Jadi komunikasi dan konsultasi yang dilakukan oleh struktur oraganisasi pengelola risiko dalam unit pemilik risiko kantor wilayah direktorat perbendaharaan provinsi nusa tenggara barat sudah dilakukan sebanyak 36 kali rapat bulanan, 12 kali rapat triwulanan, 6 kali rapat semesteran.

b. Penetapan konteks

Penetapan konteks dilakukan dengan cara menjabarkan tujuan,mendefinisikan parameter internal dan eksternal yang akan dipertimbangkan dalam mengelola risiko, serta menetapkan cakupan dan kriteria risiko untuk proses selanjutnya. Penetapan konteks ini bertujuan untuk memahami dan menetapkan lingkungan atau batasan dalam pelaksanaan manajemen risiko.

Pada proses ini semua risiko-risiko yang timbul akan di kategorikan dalam jenis-jenis risiko. Misalnya kategori risiko kebijakan, risiko kepatuhan, risiko legal, risiko fraud, risiko operasional dan risiko fiskal.

c. Analisis Resiko

Analisis Risiko dilakukan dengan cara menentukan tingkat konsekuensi dan tingkat kemungkinan terjadinya risiko berdasarkan kriteria risiko, dengan mempertimbangkan keandalan sistem pengendalian yang ada. Pada proses ini risiko di analisis setelah dilakukan identifikasi.

Analisis risiko ini dilakukan dengan memetakan risiko, apakah risiko tersebut 


\begin{tabular}{|c|c|c|c|}
\hline \multirow{2}{*}{$\begin{array}{c}\text { Kategori } \\
\text { Risiko }\end{array}$} & \multicolumn{2}{|c|}{ Risiko } & $\begin{array}{c}\text { Persentasi } \\
(\%)\end{array}$ \\
\cline { 2 - 3 } & $\begin{array}{c}\text { Kejadian,Peny } \\
\text { ebab, Dampak }\end{array}$ & $\begin{array}{c}\text { Penyebab } \\
\text { keseluruhan }\end{array}$ & \\
\hline $\begin{array}{c}\text { Risiko } \\
\text { Kebijakan }\end{array}$ & 2 & 148 & $1,35 \%$ \\
\hline $\begin{array}{l}\text { Risiko } \\
\text { kepatuhan }\end{array}$ & 4 & 148 & $2,7 \%$ \\
\hline Risiko Legal & 1 & 148 & $0,67 \%$ \\
\hline Risiko fraud & 2 & 148 & $1,35 \%$ \\
\hline Risiko reputasi & 1 & 148 & $0,67 \%$ \\
\hline $\begin{array}{c}\text { Risiko } \\
\text { Operasional }\end{array}$ & 138 & 148 & $93,24 \%$ \\
\hline
\end{tabular}

berwarna merah merah, orange, kuning, hijau, dan biru. Kemudian analisis risiko dilakukan menggunakan matriks analisis risiko sehingga dapat diketahui level dampak dari risiko tersebut apakah tidak signifikan, minor, moderat, signifikan, sangat signifikan.

d. Mitigasi Risiko (pengendalian/penanganan risiko)

Mitigasi Risiko dilakukan dengan mengidentifkasi berbagai opsimitigasi risiko. Opsi yang dimaksud yaitu: mengurangi kemungkinan terjadi risiko, menurunkan dampak terjadinya risiko, mengalihkan risiko, menghindari risiko, dan menerima risiko. Opsi tersebut harus dipilih dan diterapkan untuk memitigasi risiko, dilanjutkan dengan menyusun rencana mitigasi risiko dan pelaksanaan rencana mitigasi risiko. Mitigasi ini dilaksanakan oleh Unit Pengelola Risiko Lingkup Kantor Wilayah Durektorat Jenderal Perbendaharaan Provinsi Nusa Tenggara Barat.

Pada proses mitigasi ini semua risiko yang sudah diidentifikasi dan dianalisis risikonya harus sesuai dengan tingkat/level risiko dan mengambil langkah yang tepat untuk meminimalisir risiko yang akan timbul dimasa yang akan datang.

e. Pemantauan (monitoring) dan reviu

Pemantauan dan reviu dilakukan terhadap seluruh aspek dari Proses Manajemen Risiko. Pemantauan dan reviu ini bertujuan untuk memastikan bahwa implementasi manajemen risiko ini berjalan dengan efektif sesuai dengan rencana dan memberi umpan balik kepada organisasi dalam mencapai tujuan dan sasarannya.

Jadi menurut peneliti proses manajemen risiko pada Kantor Wilayah Direktorat Jenderal Perbendaharaan Provinsi Nusa
Tenggara Barat sudah diterapkan cukup baik karena berdasarkan teori yang dikutip oleh Idroes (2008: 7), dimana proses pertama yaitu identifikasi risiko, menilai risiko, menegaskan profil risiko, implementasi tindakan mitigasi dan pemantauan ulang risiko.

Tabel 4.2 Profil Risiko

Berdasarkan tabel diatas, dapat diketahui bahwa jumlah risiko yang paling rendah yaitu risiko Legal dan risiko Reputasi yang memiliki persentasi yang sama sebesar $0,67 \%$ dengan kejadian sebanyak 1 kali kejadian dari 148 kejadian yang ada, sedangkan untuk risiko yang paling tinggi diantara resiko yang terjadi pada Kantor Wilayah Direktorat Jendral Perbendaharaan Provinsi NTB yaitu risiko Operasional yang diidentifikasi sebanyak 93,24\% dengan total kejadian sebanyak 138 kejadian dari total keseluruhan 148 penyebab risiko.

Dari hasil data primer dan sekunder dapat disimpulkan bahwa risiko yang terjadi hanya bersifat risiko ringan yang dapat mendukung operasional kantor agar tujuan dapat terealisasi dengan baik. Walaupun risiko yang terjadi pada Kantor Wilayah Direktorat Jendral Perbendaharaan Provinsi Nusa Tenggara Barat bersifat risiko ringan, penanganannya harus tepat dikarenakan resiko operasional yang tidak ditangani dengan tepat dapat menimbulkan masalah atau risiko yang lain yang dapat merugikan kantor.

\section{Simpulan}

Implementasi manajemen pengendalian risiko Pada Kantor Wilayah Direktorat Jenderal Perbendaharaan Provinsi Nusa Tenggara Barat telah berjalan sesuai 2 variabel indikator. Indikator pertama Komunikasi, sudah dilakukan dengan rapat setiap bulan, rapat triwulanan, dan rapat pada setiap semeter. Yang kedua sumberdaya yang ada pada Kantor Wilayah Direktorat Jenderal Perbendaharaan Provinsi Nusa Tenggara Barat dari jumlah, jenjang pendidikan, dana dan fasilitas kantor.

Proses Implementasi manajemen pengendalalian risiko sudah dilaksanakan dengan baik mulai dari komunikasi dan konsultasi, penetapan konteks, penilaian risiko (identifikasi risiko, analisis risiko, evaluasi risiko), pengendalian (mitigasi), dan pemantauan (monitoring) mereviu ulang risiko.

Unit pengelola Risiko Kantor Wilayah Direktorat Jenderal Perbendaharaan Provinsi Nusa Tenggara Barat, melakukan pengendalian/penanganan (mitigasi) risiko 
dengan dua solusi yaitu dengan mengurangi kemungkinan terjadinya risiko dan menurunkan dampak risiko. Mengurangi kemungkinan terjadinya risiko yaitu pengendalian/penanganan terhadap penyebab risiko agar peluang terjadinya risiko semakin kecil. Opsi ini dapat diambil dalam hal penyebab risiko tersebut dalam kontrol internal Unit Pemilik Risiko. Dan menurunkan dampak risiko yaitu pengendalian/penanganan terhadap penyebab risiko agar peluang terjadinya risiko semakin kecil. Dengan demikian tujuan serta sasaran/tujuan organisasi Kantor Wilayah Direktorat Jenderal Perbendaharaan Provinsi Nusa Tenggara Barat dapat tercapai tanpa adanya hambatan yang dapat mengganggu pada proses pencapaian tujuan organisasi.

\section{Saran}

1. Bagi Kantor Wilayah Direktorat Jendertal Perbendaharaan Provinsi Nusa Tenggara Barat untuk tetap mempertahankan penerapan manajemen risiko dalam upaya tercapainya tujuan organisasi bila perlu ditingkatkan lagi untuk memajukan instansi agar lebih efektif dan efisien.

2. Bagi peneliti selanjutnya, diharapkan penelitian ini dapat dijadikan litelatur dalam penelitian berikutnya yang akan meneliti tentang implementasi manajemen risiko dalam upayatercapainya tujuan organisasi.

\section{Daftar Pustaka}

[1] Agustino, Leo. 2008. DasardasarKebijakanPublik. Bandung: Alfabeta

[2] Ahmadi, Rulam, Drs. Dr. 2014., metodologi penelitian kualitatif, Yogyakarta: Ar Ruzz Media

[3] Berg, Heinz-Peter.2010. Risk Management: Procedures, Methods, and Experiences. Journal RT\&A

[4] Darmawi, Herman, 2016. Manajemen Risiko Edisi 2. Jakarta: Bumi Aksara, hal82

[5] Idroes, Ferry N, 2008. Manajemen Risiko Pebankan:Pemahaman Pendekatan 3 Pilar Kesepakatan Basel II Terkait Aplikasi Regulasi Dan Pelaksanaannya Di Indonesia, Jakarta: Rajawali

[6] Kanchu, Thirupathi \& Kumar, M. Manoj. 2013. Risk Management in Banking Sector-An Empirical Study. International Journal of Marketing, Financial Service \& Management Research, 2(2):145-153.
[7] Karim, Riduan. 2004. Prinsip-Prinsip Manajemen Risiko. Jurnal Iqtishad, Vol 4 ( 12): 64

[8] Kleffner, A. E., Lee, Ryan B., \& McGannon, Bill. 2003. The Effect of Corporate Governance The Use Of Enterprise Risk Management: Evidence From Canada. Canada: Risk Management and Insurance Review, 6(1):5373.

[9] Lestari Rini, 2013. Pengaruh Manajemen Risiko Terhadap Kinerja Organisasi, Skripsi Malayu

[10] S.P. Hasibuan, Drs. H.2007., Organisasi \& Motivasi, PT Bumi Aksara: Jakarta

\section{Peraturan Perundang-undangan}

Keputusan Menteri Keuangan (Kepmenkeu). 2005, Pedoman Strategi dan Kebijakan Departemen Keuangan (Road-map Departemen Keuangan) No. 464/KMK.01/2005.Jakarta.

$\checkmark$ Keputusan Menteri keuangan (Kepmenkeu). 2016. Petunjuk Pelaksanaan Manajemen

Risiko Dilingkungan Kementerian Keuangan. NOMOR 845/KMK.01/2016

$\checkmark$ Keputusan menteri keuangan (kepmenkeu). 2016. Organisasi dan Tata Kerja Instansi Vertikal Direktorat Jenderal Perbenharaan. NOMOR262/PMK.01/2016

$\checkmark$ Keputusan Direktur Jenderal Perbendaharaan. 2016. Pedoman Pelaksanaan Manajemen Risiko Dilingkungan Direktorat Jenderal Perbendaharaan. NOMOR KEP796/PMK.01/2016 